\title{
X-Band Microstrip Bandpass Filter Design using Square Loop Resonator and Defected Ground Structure
}

\author{
Edwar $^{* *}$, D. Arseno ${ }^{1}$ and M. R. Yusron ${ }^{1}$ \\ ${ }^{1}$ School of Electrical Engineering, Telkom University, Bandung, 40287, Indonesia \\ *edwarm@telkomuniversity.ac.id
}

Manuscript received April 19, 2020; revised October 10, 2020; accepted December 2, 2020

\begin{abstract}
Filter is an important part in telecommunication system including in radar system. To get a better performance in selecting the signal, a filter must have a good Q-Factor. In this paper, an investigation of a filter design for synthetic radar has been successfully done. This filter has been designed to work at $\mathrm{x}$-band using square loop resonator (SLR). A Defected Ground Structure (DGS) has been implemented to this work to increase the $Q$-factor of the filter. It is obtained that the best performance occurs when the center frequency is at $9.51 \mathrm{GHz}$ with the bandwidth of $610 \mathrm{MHz}$ and PCB size of this filter is $22 \mathrm{~mm} \times 16 \mathrm{~mm}$.
\end{abstract}

Keywords: Filter; Square Loop Resonator; Defected Ground Structure

doi: 10.25124/jmecs.v7i1.2037

\section{Introduction}

Filter is one of important component in telecommunication device which has responsibility to select signals that passe through and attenuate the unwanted one. Filter can be built using several techniques and material, depend on the application. The one that is popular among small communication device application is the microstrip filter.

There are so many models and methods of microstrip filter that have been developed to this day. These developments and modifications are made to get better filter performance and smaller filter sizes. One of the development methods and models is Square Loop Resonator (SLR). This filter has the compact and small size that is placed on the top of the substrate [1]. To get a better performance, a filter must have a good Q-factor value. Several studies have been done $[1,2]$ to increase the Q-factor value by modifyingthe capacitive gap between the feed and the resonator.

This study utilizes Defected Ground Structure (DGS) to increase the Q-factor. DGS is a structure that can improve the microstrip device performance and has been implemented to enchance the antenna gain $[3,4]$ as well as to increase the bandwidth of BPF filter [5-8]. Previous research shows that the DGS is also capable to increase the selectivity of filter response [9]. Therefore, this prevents any signal from another unwanted spectrum which disturbs or interferences the main operation frequency.

The DGS has a various design such as rectangular dumbbell, spiral, meandel line, etc [5]. The rectangular dumbbell is the most simple structure. However, it has a single stop band response that is not adequate enough for a band pass filter. To overcome that problem, a periodic type of rectangular dumbbell DSG structure is proposed to increase its selectivity performanc especially for band pass application due to its better response at the lower and higher cut off frequency. In this paper, a SLR filter with the the periodic rectangular dumbbell DGS structure is presented. This DGS structure has been selected due to its simplicity. This filter works in X-band with center frequency at $9610 \mathrm{MHz}$. 


\section{Theory Overview}

\subsection{Microstrip Structure}

Microstrip is one of transmission media used to work on high frequency such as radio communication device or radar. Generally, microstrip structure consists of the conductor strip (microstrip line) which has a width $(W)$ and the thickness of the $(h)$. It is printed on the dielectric which has typical dielectric constant $\varepsilon_{r}$ and has a thickness $h$. The bottom side is the ground conductor plane [10]. The Fig. 1 shows the structure of a microstrip. Due to the nature of microstrip, it guides the electromagnetic wave to propagate in two different media, air and the dielectric, simultaneously. Thus, the term 'epsilon effective' constant of $\varepsilon_{r}$ is introduced. To get the value of $\varepsilon_{r}$ can search with Eq. 1 for $W / h \leq 1[10]$.

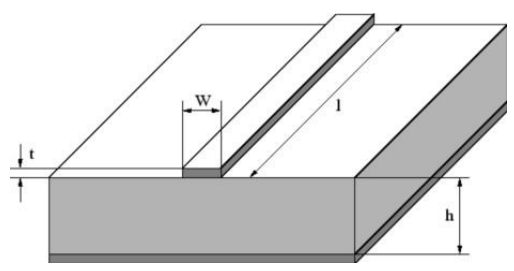

Fig. 1. Microstrip Structure

$$
\begin{aligned}
\varepsilon_{r e}= & \frac{\varepsilon_{r}+1}{2}+\frac{\varepsilon_{r}-1}{2}\left(1+12 \frac{h}{W}\right)^{-0.5}+ \\
& 0.04\left(1-\frac{W}{h}\right)^{2}
\end{aligned}
$$

The $Z_{c}$ is following the Eq. 2 with the $\eta$ is the $120 \pi$.

$$
Z_{c}=\frac{\eta}{2 \pi \sqrt{\varepsilon_{r e}}} \ln \left(\frac{8 h}{W}+0.25 \frac{W}{h}\right)
$$

The $W / h$ value can be obtained from Eq. 3

\subsection{Square Loop Resonator (SLR)}

The SLR is one of resonator design which able to be used for microstrip filter. It has square form factor and relatively compact dimension. Fig 2 shows the form of the basic of the SLR structure. The length of each side of the resonator $(l)$ is calculated by Eq. 3 .

$$
l=\frac{\lambda}{4}
$$

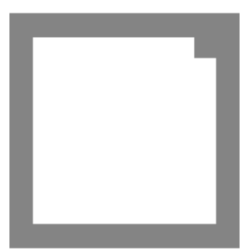

Fig. 2 Square Loop Resonator Shape

\subsection{Defected Ground Structure}

Defected ground structure is a development technique of Electromagnetic Band Gap (EBG) in designing microstrip by doing the addition of one or several compact geometrical shape on the ground plane of his connected on line transmission. By adding DGS on the ground plane can change the characteristics of the transmission line skipped by electromagnetic waves due to the change in value on the parameter (such as inductor area, capacitor and resistor installed in the slot ground) [5].

The advantage of by using DGS is able to provide the value of the insertion loss and return loss the more optimal, easy to manufacture and have the same size. In addition to performing the addition of DGS can provide better results from the does not use. Loss of use DGS is radiation problems. This is because power on the frequency resonance that back on the line the transmission of large enough [Analysis and Realization of Defected Ground Structure (DGS) on Bandpass Filter].

\section{Specification and Simulation Result}

The design is done by using the Rogers Duroid RT5880 with relative permittivity $\left(\varepsilon_{r}\right) \quad 2.2$ and thickness $1.575 \mathrm{~mm}$ [6]. This filter is expected to work at $9610 \mathrm{GHz}$ with bandwidth more than $300 \mathrm{MHz}$ insertion loss level more than $-3 \mathrm{~dB}$ and return loss level less than $-10 \mathrm{~dB}$. The resonator dimension is achieved from calculation using set of Equations (1)(3). From this calculation, it is obtained that the resonator's length and width are $5.8 \mathrm{~mm}$ and $2.2 \mathrm{~mm}$, respectively, and the initial length and width of feedline are $5.4 \mathrm{~mm}$ and $2.2 \mathrm{~mm}$, respectively. This initial SLR filter form has been simulated and the result, the center frequency is on $2 \mathrm{GHz}$ which is shifted from the specification. Therefore, an optimization process has been done to get a better result by modifying the filter structure. The optimization result is shown by Fig. 3 where it has been done by making the resonator and feedline thinner. Another modification is adding a capacitive gap between the resonator and feedline. 


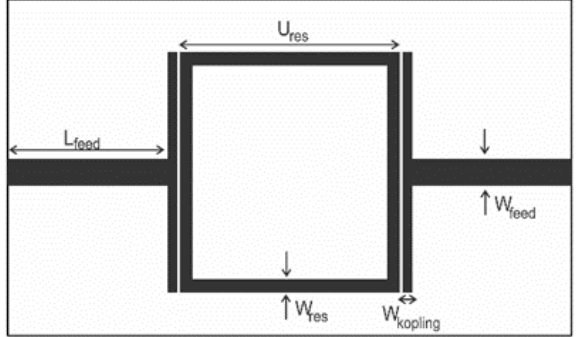

Fig. 3. SLR Filter Design

The results of the optimization is the center frequency has been successfully shifted back to 9,63 $\mathrm{GHz}$ with the bandwidth is $1.313 \mathrm{GHz}$. The value of the insertion loss and return loss are $-1.03 \mathrm{~dB}$ and $28.39 \mathrm{~dB}$ respectively. To increase the Q-factor of the filter, two DGS structure has been implemented on the groundplane side. The final form of this filter is shown by Fig. 4 where the dimension is explained in the Table. 1

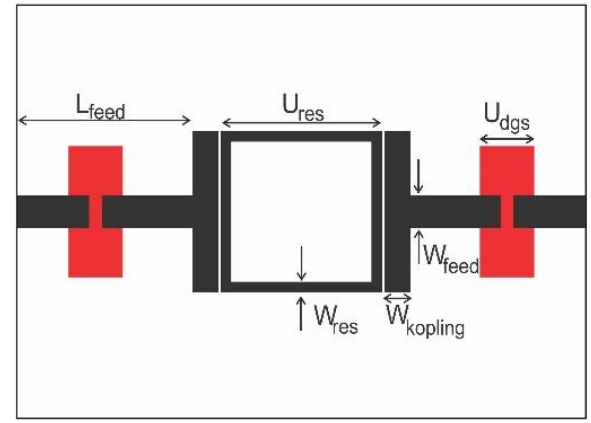

Fig. 4. SLR Filter with DGS

\section{Simulation and Measurement Result}

The final design DGS simulation shows that the filter with DGS has smaller bandwidth than the one without DGS. It means the rising Q-factor is increased. b. The comparison of before and after the addition of DGS is shown by Fig 5 (a) and (b)The center frequency of this filter is $9.607 \mathrm{GHz}$ filter with the bandwidth is $589.7 \mathrm{MHz}$, almost $50 \%$ shrank down from the previous design. The insertion loss and return loss are $-2.0578 \mathrm{~dB}$ and $-18.1 \mathrm{~dB}$ respectively.

To examine the performance of the fabricated filter, the measurement has been conducted and the results ara shown in. The fabrication results filter has the size of $22 \mathrm{~mm} \times 16 \mathrm{~mm}$ as shown in Fig. 6 and Fig. 7.
Table 1. Filter Dimension

\begin{tabular}{|c|c|}
\hline Variable & Size \\
\hline$U_{\text {res }}$ & $7.15 \mathrm{~mm}$ \\
\hline$W_{\text {res }}$ & $0.4 \mathrm{~mm}$ \\
\hline$L_{\text {feed }}$ & $6.785 \mathrm{~mm}$ \\
\hline$W_{\text {feed }}$ & $1.26 \mathrm{~mm}$ \\
\hline$W_{\text {coupling }}$ & $1 \mathrm{~mm}$ \\
\hline$U_{\text {dgs }}$ & $2.1 \mathrm{~mm}$ \\
\hline
\end{tabular}

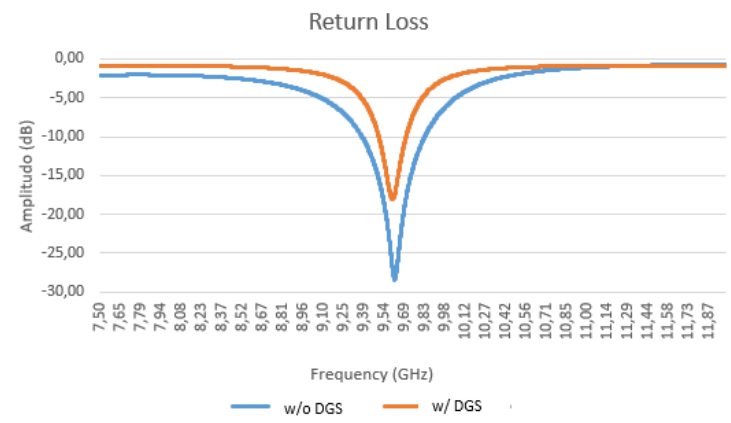

(a)

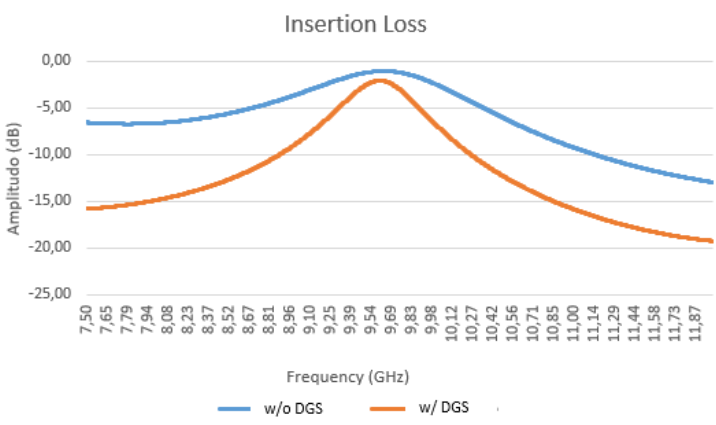

(b)

Fig. 5. (a) Return Loss Simulation Result with and without DGS, (b) Insertion Loss Simulation Result with and without DGS.

Fig. 8 (a) and (b) show that the center frequency of the fabricated filter is $9.51 \mathrm{GHz}$ frequency and the bandwidth is $610 \mathrm{MHz}$. The fabricated filter's bandwidth is wider than the simulation one. 
This difference is expected to be occured due to the discrepancy on the substrate thickness between the simulation and the fabrication. The insertion loss and return loss are $-2.89 \mathrm{~dB}$ and $-14.1 \mathrm{~dB}$ respectively which are slightly degradated from the simulation result. Table 2 shows the comparison result between the simulation and the measurement.

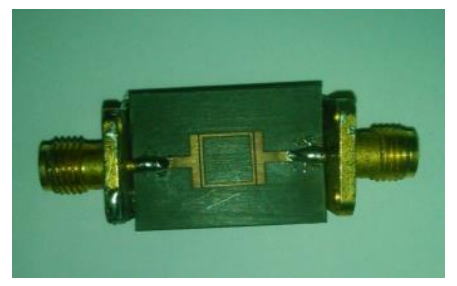

Fig. 6. Final Printed Filter (Top View)

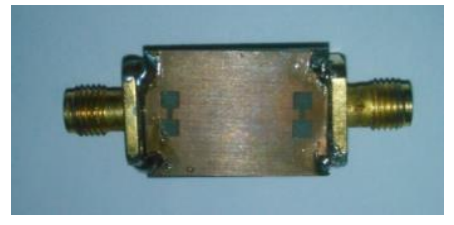

Fig. 7. Final Printed Filter (Rear View)

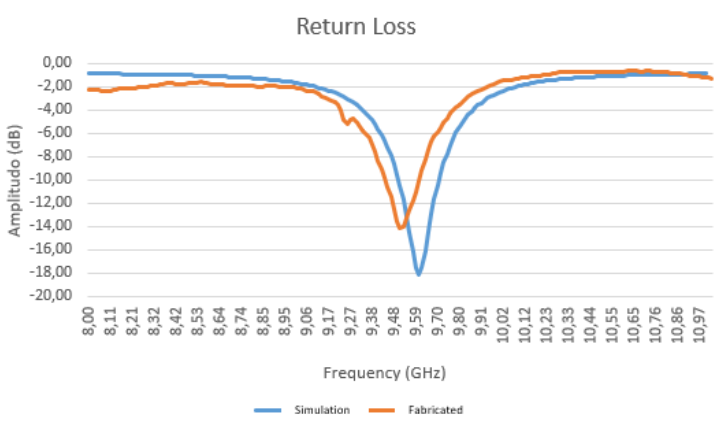

(a)

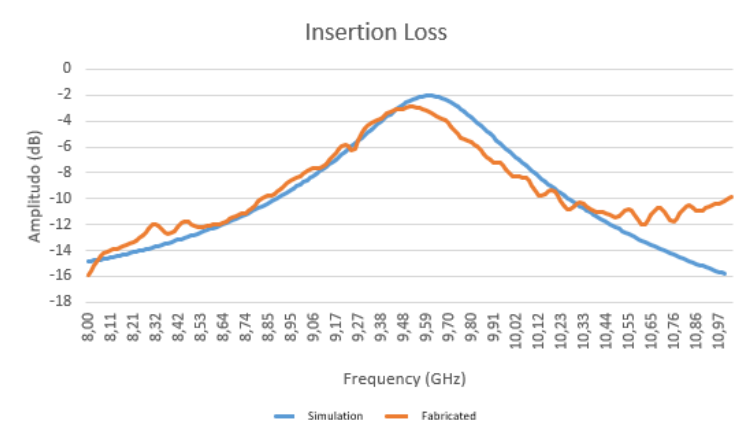

(b)

Fig. 8. (a) Return Loss Measurement result with DGS, and (b) Insertion Loss Measurement result with DGS
Table 2. Simulation and Fabrication Result Comparison

\begin{tabular}{|l|l|l|}
\hline Parameter & Simulation & Fabrication \\
\hline Frequency Center & $9.607 \mathrm{GHz}$ & $9.51 \mathrm{GHz}$ \\
\hline Bandwidth & $589.7 \mathrm{MHz}$ & $610 \mathrm{MHz}$ \\
\hline Return Loss & $-18.1 \mathrm{~dB}$ & $-14.1 \mathrm{~dB}$ \\
\hline Insertion Loss & $-2.0578 \mathrm{~dB}$ & $-2.89 \mathrm{~dB}$ \\
\hline
\end{tabular}

\section{Conclusion}

The SLR with DGS bandpass filter has been designed, simulated, and tested The DGS has made filter response more selective and get narrower bandwidth. The filter has a center frequency of 9.51 $\mathrm{GHz}$ and $610 \mathrm{MHz}$ bandwidth. The insertion loss value is $-2.89 \mathrm{~dB}$ and the return loss value is $-14.1 \mathrm{~dB}$.

\section{References}

[1] Edwar, M. A. Wibisono, A. Munir, "Microstrip BPF Made of Square Loop Resonator for X-Band Weather Radar", 2nd International Conference on Wireless and Telematics (ICWT), 2016.

[2] B. Syihabuddin, D. A. Nurmantris, A. D. Prasetyo, "Perancangan Bandpass Filter Pita Sempit pada Frekuensi L-Band untuk Aplikasi Synthetic Aperture Radar (SAR)", INFOTEL, vol. 9, no. 2, pp. 198-203, May 2017.

[3] D. P. Wulandari, H. Wijayanto, Edwar, "An Investigation of Defected Ground Structure Effect on Bandwidth Enhancement of UShape Microstrip Antenna for Small Ultra Wide-Band Radar Device", Journal of Measurements, Electronics, Communications, and Systems (JMECS), Vol. 5, p. 20-25, 2019.

[4] M. Yunus, Z. L. Patriana, E. Wismiana; T. Firmasyah, B. Syihabuddin, A. Munir, "Incorporation of Spiral Shaped Defected Ground Structure for Improving Radiation Characteristic of Planar Array-Antenna", Conference on Antenna Measurements \& Applications (CAMA), 2019. 
[5] S. F. Nurjihan, A. Munir, "Rancang Bangun Filter Bandpass Mikrostrip Pita Sangat Lebar Berbasis Defected Ground Structure", JNTETI, Vol. 9, No. 1, pp. 104-109, 2020.

[6] A. Latip, N. Ismail, O. T. Kurahman, A. Munir, "Effect of DGS Utilization on Characteristics of Square shaped CSRR-Based SIW BPF", 5th International Conference on Wireless and Telematics (ICWT), 2019.

[7] N. Ismail, A. Latip, E. A. Z. Hamidi, A. Munir, "Defected Ground Structure for Characteristic Enhancement of CSRR-based Substrate Integrated Waveguide BPF", PhotonIcs \& Electromagnetics Research Symposium Spring (PIERS-Spring), 2019.

[8] M. K. Khandelwal, B. K. Kanaujia, S. Kumar, "Defected Ground Structure: Fundamentals, Analysis, and Applications in Modern Wireless Trends," International Journal of Antennas and Propagation, Vol. 2017, 2017.

[9] M. T. Khan, M. A. Zakariya, M. N. M. Saad, Z. Baharudin, M. Z. Ur Rehman, "Analysis and Realization of Defected Ground Structure (DGS) on Bandpass Filter", 5th International Conference on Intelligent and Advanced Systems (ICIAS), 2014.

[10] M. J. Lancaster. J. S. Hong, Microstrip Filters for RF/Microwave Aplication, $2^{\text {nd }}$ ed, Jhon Willey and Son, 2011.

[11] R. Coproration, "RT/duroid $5870 \quad / 5880$ Datasheet". 2016.

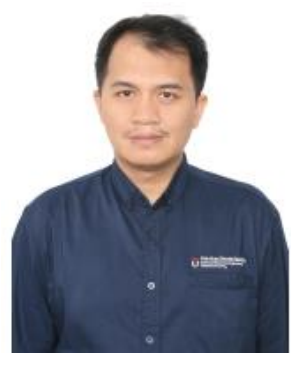

Edwar, He finished his bachelor degree in Telkom University, then continued the master degree in Bandung Institute of Technology. Currently he is a lecturer in the School of Electrical Engineering Telkom University. $\mathrm{He}$ is also the Head of Electronic of Telecommunication Laboratory and the member of Nanosatellite Laboratory in Telkom University. He has interest on Nanosatellite subsystem and payload research, RF device and its application especially in remote sensing area and has been published some papers and journals in those fields on international proceeding and national journal.

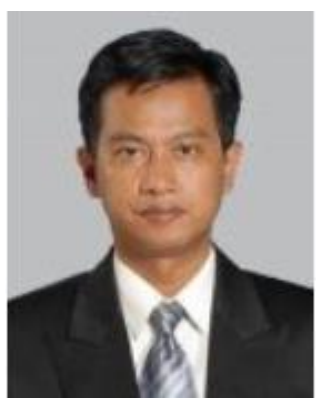

Dharu Arseno, he received bachelor degree and master's degree from the Departement of Electrical Engineering, Bandung Institute of Technology (ITB) in 1995 and 2001, respectively. Dharu is currently a senior lecturer at School of Electrical Engineering, Telkom University since 2002. His research interest is on wireless communications and radar.

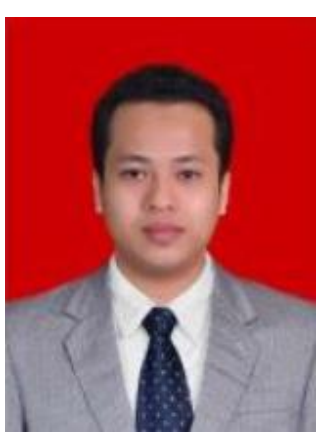

Muhammad Riza Yusron, he received bachelor degree degree from the School of Electrical Engineering, Telkom University in 2017. He was a member of Electronic of Telecommunication Research Group from 2015-2017. His research interest is on microwave devices. 